\title{
Development of a Detector to Measure the Angular Dependence of the Cosmic Ray Induced Neutron Background Flux at Ground Level
}

J.F. Morgan, T.B. Gosnell, S.J. Luke, D. Archer, R.T. Lochner, I.M. Frank, S.G. Prussin, B.J. Quiter, D.H. Chivers

January 28, 2002 


\section{DISCLAIMER}

This document was prepared as an account of work sponsored by an agency of the United States Government. Neither the United States Government nor the University of California nor any of their employees, makes any warranty, express or implied, or assumes any legal liability or responsibility for the accuracy, completeness, or usefulness of any information, apparatus, product, or process disclosed, or represents that its use would not infringe privately owned rights. Reference herein to any specific commercial product, process, or service by trade name, trademark, manufacturer, or otherwise, does not necessarily constitute or imply its endorsement, recommendation, or favoring by the United States Government or the University of California. The views and opinions of authors expressed herein do not necessarily state or reflect those of the United States Government or the University of California, and shall not be used for advertising or product endorsement purposes.

This work was performed under the auspices of the U. S. Department of Energy by the University of California, Lawrence Livermore National Laboratory under Contract No. W-7405-Eng-48.

This report has been reproduced directly from the best available copy.

Available electronically at http://www.doc.gov/bridge

Available for a processing fee to U.S. Department of Energy

And its contractors in paper from

U.S. Department of Energy

Office of Scientific and Technical Information

P.O. Box 62

Oak Ridge, TN 37831-0062

Telephone: (865) 576-8401

Facsimile: (865) 576-5728

E-mail: reports@adonis.osti.gov

Available for the sale to the public from

U.S. Department of Commerce

National Technical Information Service

5285 Port Royal Road

Springfield, VA 22161

Telephone: (800) 553-6847

Facsimile: (703) 605-6900

E-mail: orders@ntis.fedworld.gov

Online ordering: http://www.ntis.gov/ordering.htm

OR

Lawrence Livermore National Laboratory

Technical Information Department's Digital Library

http://www.llnl.gov/tid/Library.html 


\title{
Development of a Detector to Measure the Angular Dependence of the
} Cosmic Ray Induced Neutron Background Flux at Ground Level

\author{
J.F.Morgan, T.B.Gosnell, S. J. Luke, D. Archer and R.T.Lochner \\ Lawrence Livermore Laboratory \\ M.I.Frank, S.G.Prussin, BJ.Quiters and D.H.Chivers \\ University of California, Berkeley
}

The detection of low intensity sources of radiation in containers is of particular interest for arms control, non-proliferation and nuclear smuggling activities. Attempts to procure and smuggle nuclear materials that could be used in terrorist activities have been well documented in recent years. These incidents have included fissile materials such, as plutonium and uranium, as well as medical and industrial isotopes that could be used in a Radiation Dispersal Device. The vast majority of these incidents have been discovered through human intelligence work due to the difficulty of using radiation monitoring.

The detection of radiation sources in well-shielded containers presents a difficult technological challenge. Few neutrons and gamma rays may escape from the container and these may be obscured by the naturally occurring background. The world in general is a radioactive environment. Many elements in the earth's crust, as well as in common plants and building materials, emit a constant stream of radiation.

In fact the ultimate limit on the detection of hidden sources is often the background level at the location of interest. It has long been understood that knowledge of the directionality of this background can be used to improve the signal/noise ratio in detectors used for these measurements. Imaging detectors are one method of reducing the effect of the background, but this reduction comes at the expensive of a huge increase in detector complexity. Hence these systems; while important in some specific applications, are probably not suited for the deployment of many detectors over a large area.

There may be another way of reducing the effect of backgrounds on monitoring measurements. This method consists of using knowledge of the directional dependence of the background flux to help reduce its effect on the detectors in question. An accurate knowledge of this angular distribution allows one to develop better shielding designs for the detectors.

One of the two components of this background radiation consists of neutrons. This neutron component is generated by interactions of cosmic rays with the upper atmosphere, and the subsequent propagation of these neutrons to ground level. A thorough investigation of the angular dependence of this neutron flux could lead the way toward a better design for the shielding surrounding radiation detectors deployed in the field. Recently, at.the University of California Berkeley, Frank and Prussin have carried out a new calculation of the magnitude and direction of the neutron flux at ground level. This calculation takes into account both new models for the production of neutrons by the cosmic rays, and advanced codes for neutron 
transport through the atmosphere. Very few measurements of this flux have been carried out: an up-down asymmetry has been established for neutrons in the thermal range but only a single measurement of this effect has been reported. Because low-energy neutrons are the most easily detected with conventional and inexpensive detectors, a detailed knowledge of the angular distribution at these energies offers significant potential for improving the ability to detect weak sources.

It is thus very important to verify these calculations, as they can then be used to improve the design of detector systems for low-level signals. Figure 1 illustrates how knowledge of the directionality of the neutron signals can be used to greatly reduce the background in a conventional ${ }^{3} \mathrm{He}$ detector. The neutron flux into the unshielded detector is essentially isotropic if the detector is placed on bare ground or over asphalt. This is due mainly to the backscatter of low energy cosmogenic neutrons from the ground. When a thin layer of boron loaded asphalt is placed under the detector there is a significant reduction in the amount of backscattered neutrons entering the detector.

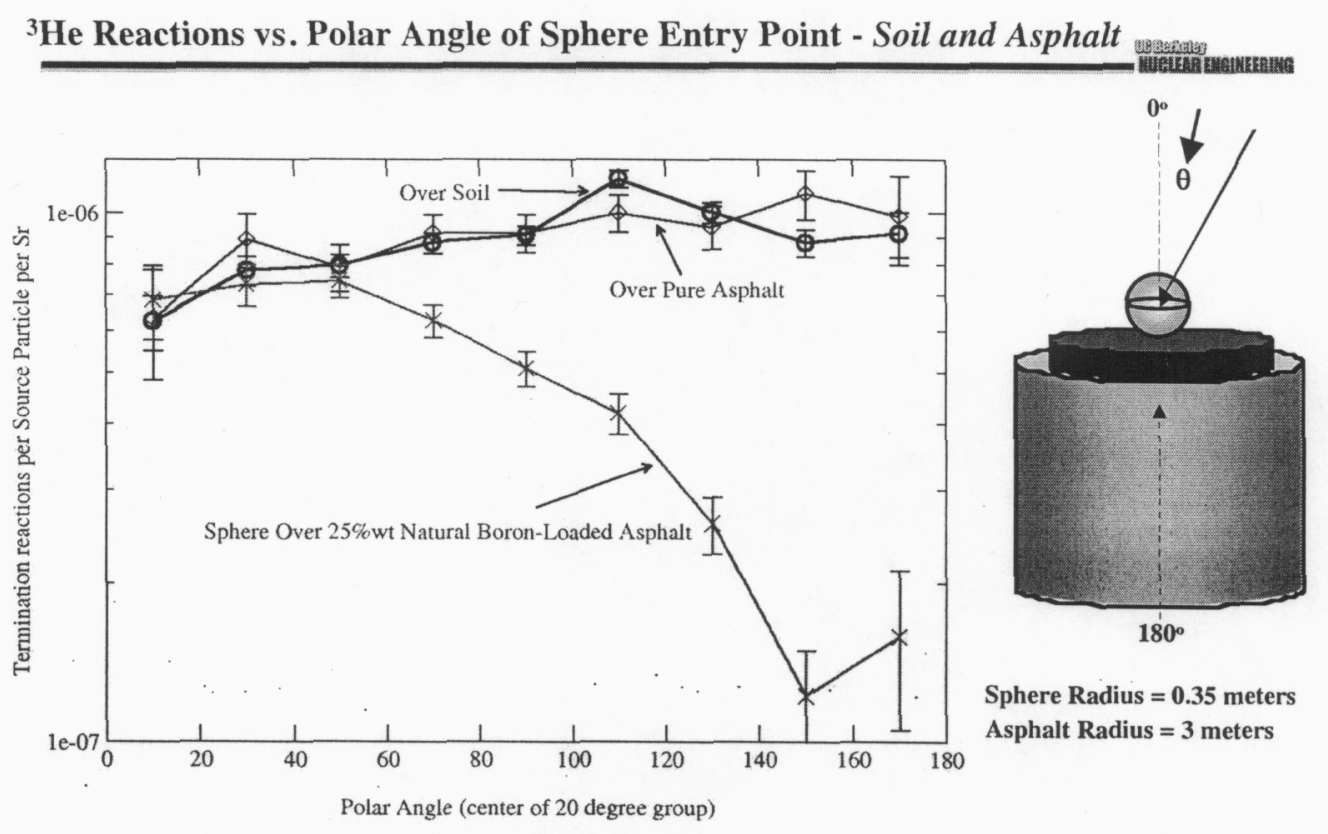

Figure 1. The neutron background into the detector can be significantly reduced by a proper choice of shielding

We developed a new, directional neutron detector, based on a concept developed by the Berkeley group, to verify these calculations. This detector is based on conventional ${ }^{3} \mathrm{He}$ detectors and a new, proprietary, Boron loaded moderator that provides the directionality. A schematic of this detector is shown in Figure 2. The Boron loaded material is rolled into a cone with an opening angle of approximately 60 degrees. The cone is mounted in a cradle that allows the detector assembly to rotate through 180 degrees. Five ${ }^{3}$ He tubes, which are 
sensitive to the flux of low-energy neutrons, are mounted at the apex of the cone. The placement of these tubes is shown in Figure 3.

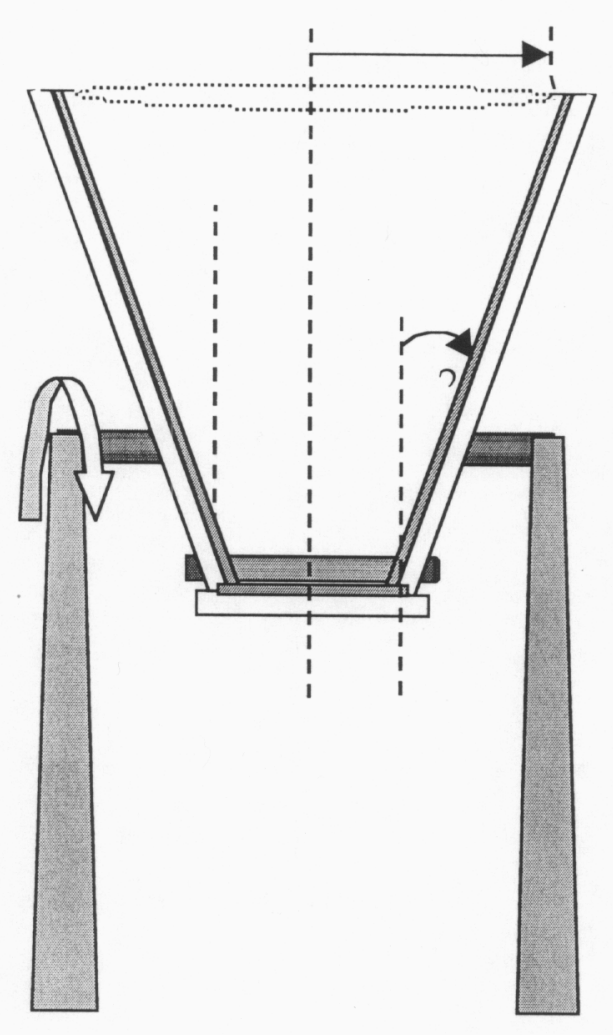

FRONT VIEW

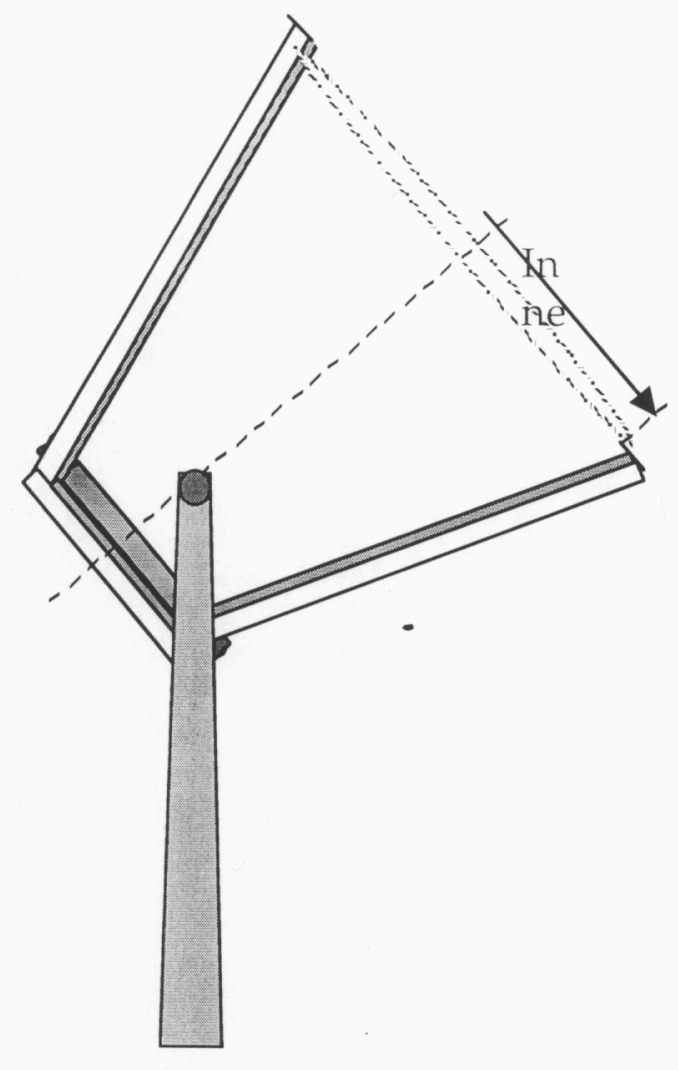

SIDE VIEW

Figure 2 Schematic of the detector 


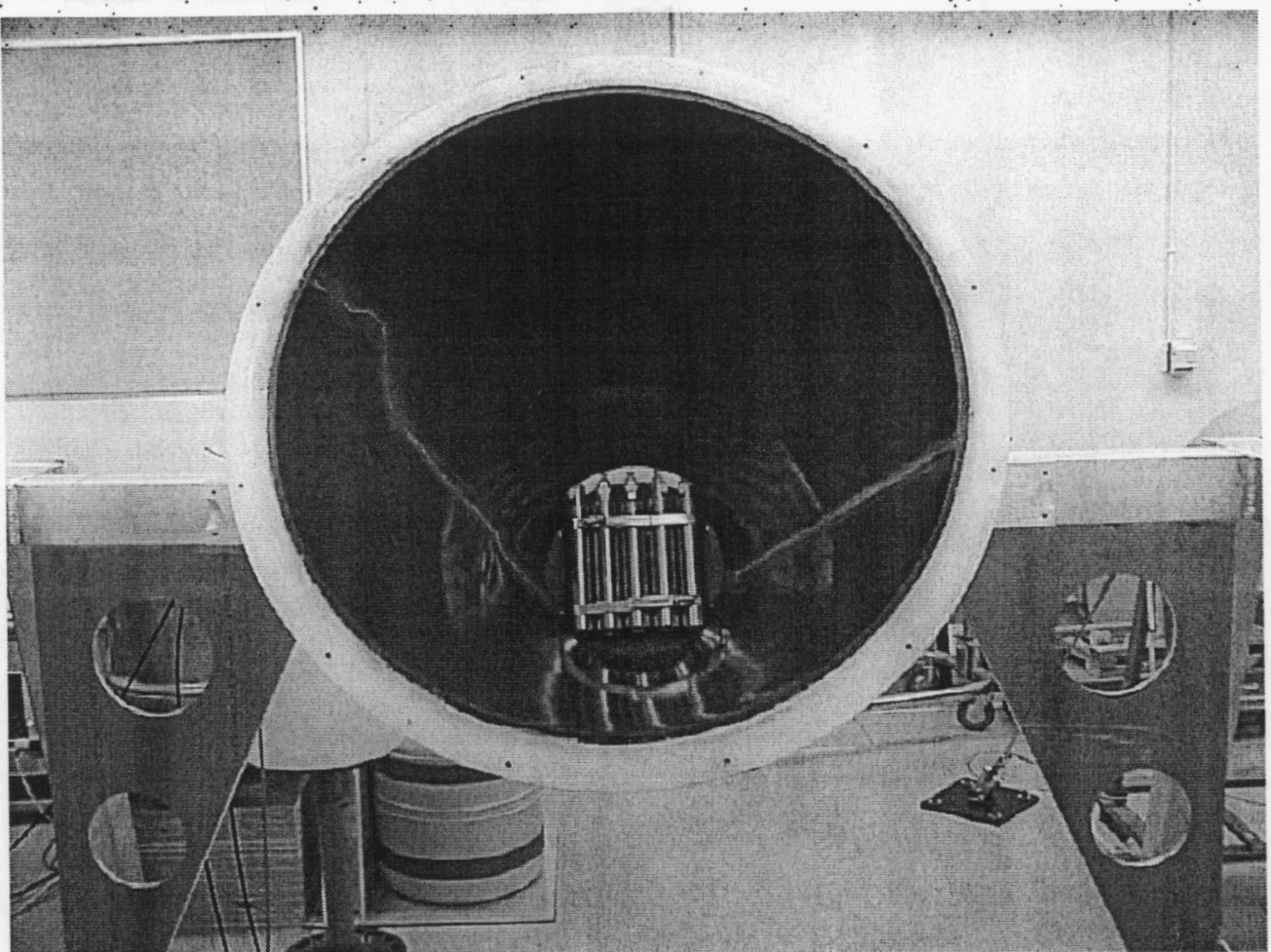

Figure 3. Placement of the ${ }^{3} \mathrm{He}$ tubes in the apex of the cone

The mechanical and electrical systems for the detector were completed under the aegis of LDRD 01-FS-008. Under the same grant we have modified an existing van to provide power in order to allow us to make measurements in remote locations. The finished detector is shown in Figure 4. Following the completion of the LDRD grant the electronic shakeout and calibration of the detector system has been completed. At this time we are preparing to make the first field measurements of the neutron flux angular distribution.

In the next year we will make preliminary measurements of the directionally resolved lowenergy neutron flux. If the calculations are confirmed we will immediately use the results to design detection systems of importance to border control and nuclear search problems. Recently we have begun discussions of using the detector to make measurements of the directional neutron flux in the Antarctic region. It is possible that this flux may have a significant effect on the geochronology developed from radiation measurements on shales from the area. 